\title{
Ações concretas e aproximações necessárias do Projovem Urbano quanto à abordagem da sexualidade.
}

Virginia lara Andrade Maistro

Vera Lucia Bahl Oliveira

\section{Resumo}

As propostas do Projovem Urbano são aliar formação e ação no interior de um espaço institucionalizado socialmente, estimular o exercício da cidadania, garantir a dignidade do ser humano, favorecer o respeito à diversidade de valores, crenças e comportamentos relativos à sexualidade, ajudar a compreender a sua dimensão saudável, a desenvolver uma consciência crítica e a tomar decisões responsáveis a seu respeito. A escola como espaço sexualizado, tem o dever de aprofundar as reflexões sobre questões que remetem à sexualidade e permitir que as dúvidas sejam abordadas sem preconceitos, para que todos possam se informar de maneira clara e objetiva, respeitando as individualidades. Mas nem sempre os educadores enfrentam com serenidade e com o tato necessário a educação sexual. Quando os educadores não tratam esse assunto de frente, quando se omitem, estão permitindo que ele continue a ser tratado só informalmente, na rua ou em casa, sem uma orientação segura.

Palavras-chave: Projovem Urbano, sexualidade, educador

\begin{abstract}
Concrete actions and approaches needed for ProJovem Urbano on the sexuality approach

The proposals of "ProJovem Urbano" are to combine formation and action in a place socially institutionalized, to encourage the citizenship, to guarantee the human dignity, to promote respect for diversity of values beliefs and behaviors related to sexuality, to help the comprehension about their healthy dimension, to develop a critical awareness and to make decisions about theirself. The school as a social place where the sexuality questions are always showing up must do more deliberations about needs related with sexuality and allow to broach this subject without prejudice, to inform everyone clearly and objectively respecting the individualities. But it is not always that the educators face the sexuality with the serenity and sensibility required for this subject. When educators don't address this issue head-on, when they are omissive, they are allowing it to continue to be dicussed only informally in the street or at home without a safe guidance.
\end{abstract}

Keywords: Projovem Urbano, sexuality, educator

\section{Introdução}




\section{Nossas experiências...}

Durante o curso superior de Ciências Biológicas que perfizemos, em nenhum momento deparamo-nos com qualquer área do conhecimento que falasse sobre sexualidade e, muito menos, sobre projetos que envolvessem educação sexual. Tivemos de nos virar sozinhas buscando em cursos de extensão universitária, em eventos, em livros e na dissertação de mestrado de uma das autoras, o que de fato sustenta os projetos e especificamente aquele que trata sobre a temática da sexualidade no âmbito escolar, qual a metodologia usada, os obstáculos e facilidades (se é que existem) neles encontrados e os caminhos a serem seguidos.

Descobrimos, após as muitas experiências que tivemos ao longo do exercício do magistério, que o que fazíamos em sala de aula, até então, não passava de uma visão reducionista da educação sexual e de um biologismo, isto é, eram aulas expositivas sobre o aparelho reprodutor feminino e masculino, sobre doenças sexualmente transmissíveis (DST) e sobre métodos anticoncepcionais, exatamente os temas apresentados nos livros didáticos e de modo não muito diferente do usado por professores de décadas atrás. O que existia de diferente era a presença de ambos os sexos e isso achávamos que era suficiente.

Algumas vezes, convidávamos algum médico para falar sobre as infeç̧ões sexualmente transmissíveis (IST). Não víamos resultados e isso nos levou a crer que, de certo modo, essas tentativas eram infrutíferas, pois eram desvinculadas da realidade dos jovens, não levavam em conta o meio sociocultural em que eles vivem, assim como seus valores, anseios, sentimentos, preconceitos, costumes e crenças. Portanto, ao educando não era dada a chance de expor seus conhecimentos, suas angústias, suas dúvidas e medos. E só podia dar nisto: insatisfação, tanto nossa, quanto deles.

É inegável a importância do estudo sobre sexualidade na vida dos seres humanos, pois ela é experimentada ou revelada em expectativas, imaginações, anseios, crenças, posturas, valores, atividades práticas, papéis e convivências. Abrange, além do nosso corpo, nossa história, nossos costumes, nossas relações afetivas, nossa cultura. É uma das dimensões do ser humano que abarca gênero, identidade sexual, orientação sexual, erotismo, envolvimento emocional, amor e reprodução.

Sabe-se que falar sobre sexualidade por si só já é um desafio, as resistências são muitas, exigindo de todos os envolvidos revisar conceitos, superar preconceitos e estereótipos, olhar reflexivamente sobre a própria sexualidade, lidar com tabus, medos, vergonhas.

Quando o tema é a sexualidade, ainda encontramos tabus, preconceitos e negativa em discuti-lo. Muitos não o querem tratar por considerá-lo expressão do pecado ou sujeira, mostrando ignorância, carregando bloqueios ou tabus. 


\section{0 contexto escolar e a abordagem da sexualidade}

O recente movimento que tem surgido em nível mundial, por um lado, promovendo um maior nível de saúde nas populações e, por outro, considerando os jovens como grupo vulnerável, que traz, entre outros, problemas relacionados com a sexualidade, tais como o início precoce de uma vida sexual, a gravidez não desejada e doenças sexualmente transmissíveis, alertou para a necessidade de existir no âmbito escolar um espaço formal onde os alunos tivessem oportunidade de expor as suas questões, suas dúvidas e interesses. É necessário haver espaço para que este tema seja perguntado, discutido, questionado, apropriado e vivido de forma singular por cada indivíduo. A sexualidade, apesar de ser parte fundamental e integrante da vida de todos nós, os tabus a ela relacionados e as dificuldades de conversar sobre o tema ainda são muito grandes.

Em Oliveira e Lira (2008) encontramos estes dizeres:

Embora sejam vistos como os depositários das possibilidades de mudança, de um melhor prognóstico para o mundo, adolescentes são percebidos pelos adultos em geral como sujeitos que não têm autonomia frente aos seus direitos e desejos nos campos da sexualidade e reprodução. Pais, professores, líderes religiosos e profissionais de saúde acabam por estabelecer valores dicotômicos e ambíguos em relação a eles: esperam que sejam sujeitos responsáveis por suas vidas - na esfera civil, na escola, quanto ao respeito às regras em geral; entretanto, parecem não reconhecer a legitimidade dos seus direitos e as possibilidades decorrentes do exercício desses direitos, principalmente quando se trata de assuntos como contracepção, exercício da sexualidade, aborto, gravidez, maternidade/paternidade, entre outros.

Averiguando a literatura existente, notamos que existe um número considerável de trabalhos elaborados com vistas a subsidiar os educadores quanto à abordagem de assuntos que remetem à sexualidade na escola. Contudo, observamos que são poucas as instituições de ensino que incluem em suas práticas pedagógicas um projeto em que a temática sexualidade é discutida; algumas delas, quando dizem que a discutem, resumem-na a palestras a cargo de psicólogos, enfermeiros e/ou médicos e a fixar folders nos corredores, como se isso fosse suficiente para esclarecer as dúvidas a ela relacionadas e às suas múltiplas expressões.

Compreende-se que a maior parte das informações que os adolescentes têm, vem de seus próprios colegas. A televisão, conquanto seja fonte de informação, nem sempre trata desse assunto adequadamente, uma vez que apresenta filmes e vídeos musicais que exibem cenas de sexo explícitas, levando os adolescentes a emitir valores, registrando imagens que não correspondem à realidade e apropriando-se de informações inadequadas e repletas de falsas crenças. Entretanto, a ação da mídia pode ser altamente instrutiva e positiva, como têm sido os casos de transmissão de mensagens sobre a violência, a exploração sexual infantil, a AIDS etc. 
Verifica-se, também, que elevado número de adolescentes sexualmente ativos nunca falou com seus pais sobre essas questões e quando são abordadas se mostram nervosos ou receosos. E por ser muitas vezes difícil e embaraçoso este diálogo, é que um projeto que trate desta temática no âmbito escolar e uma informação adequada disponível na comunidade exercem um papel tão importante nessa fase da vida. Assim, para que a comunicação com o adolescente possa ocorrer, tanto em casa como no meio escolar, deve ser proporcionado um ambiente de compreensão ou de genuína empatia e de aceitação e respeito pelo jovem e por suas dúvidas, sem fazer julgamentos de valor delas. Os pais e os professores também podem ter dificuldades em falar sobre a sexualidade em geral ou sobre algum tema em particular. Para evitar que isso interfira no diálogo, ou o dificulte, é necessário que se preparem.

Segundo os Parâmetros Curriculares Nacionais, a princípio, acreditava-se que as famílias apresentavam resistência à abordagem dessas questões no âmbito escolar, mas atualmente sabese que os pais reivindicam a discussão sobre os mais diversos temas que envolvem a sexualidade nas escolas, visto que reconhecem não só a sua importância para crianças e jovens, como também a própria dificuldade de falar abertamente sobre esse assunto em casa. (BRASIL, 1997, v. 10, p. 111)

Professores e alunos frequentemente vivenciam e discutem esses temas, se não formalmente, em programas específicos ou em aulas de Ciências ou de Biologia, pelo menos informalmente, nas conversas e relacionamentos entre estudantes no cotidiano escolar e nas reuniões pedagógicas dos docentes. O interesse sobre eles, no contexto escolar, reforça a característica multidimensional do processo de ensino/aprendizagem, mostrando que o desenvolvimento cognitivo do indivíduo está estreitamente relacionado e, portanto, influenciado por seu desenvolvimento pessoal e social. Nele a sexualidade e a afetividade têm papéis fundamentais. A sexualidade está presente em nossa vida desde o momento em que nascemos até nossa morte. A educação acontece constantemente, seja em casa, seja através da mídia diante da televisão, em revistas e jornais, seja na internet etc. Nesse caso, se a instituição escolar se omite deliberadamente em relação a tudo que se refere a sexo e a sexualidade, essa atitude reflete na formação dos alunos, levando-os a considerar que essa temática é alguma coisa de secreto, que é um assunto que não cabe dentro da escola ou talvez seja algo vergonhoso sobre o qual não se deve falar.

Percebe-se que muitos educadores não estão preparados ou não se sentem à vontade para trabalhar esses assuntos e, desse modo, fica difícil tratá-los com tranquilidade; é melhor ignorar o que está acontecendo com relação à sexualidade dos alunos. "[...] existem professores que afirmam que sua tarefa exclusiva na escola consiste em ensinar certos conteúdos conceituais e não têm por que se preocupar se seus alunos escovam bem ou mal os dentes [...] essa situação de desprezo às matérias transversais às vezes torna patente um defeito no trabalho profissional dos professores" (GAVIDIA, 2002, p. 24). Mas seria interessante que estes se envolvessem e 
vencessem as barreiras que ainda existem e impedem que todas as crianças e adolescentes possam receber informações, debater e refletir sobre essas questões, tão fundamentais na vida de todas as pessoas.

O contexto escolar desempenha um papel importante na orientação dos alunos, todavia ainda percebemos que existem instituições que reprimem certos comportamentos dos alunos e nem sempre os educadores enfrentam com serenidade e com o tato necessário brincadeiras e comportamentos de ordem sexual, e, por vezes, atribuem uma gravidade e um caráter que na realidade não têm. Não se pode fugir da abordagem da sexualidade no contexto escolar, afirmando a sua incapacidade ou dificuldade de tratar esse assunto, porque é uma realidade os alunos expressarem-se sobre ela nos bilhetinhos, nas conversas paralelas, ou por outros meios. Quando os educadores não tratam esse assunto de frente, quando se omitem, estão permitindo que ele continue a ser tratado só informalmente, na rua ou em casa, sem uma orientação segura.

Abordar esse assunto não é função só da família, já que na maioria das vezes ela não sabe como lidar com essa questão e não tem o controle dos meios, da informação e dos estímulos que vêm de todos os lados. Por isso a comunidade escolar tem que tratar desse assunto, para não deixar os jovens na dependência de fontes informais, de pessoas que passam em sua vida, dos amigos, do que leu ou assistiu ou da própria família. O jovem fica à mercê de experiências que provavelmente não vão ajudá-lo a vencer os medos, as ansiedades, as dúvidas e responder aos questionamentos que vão surgindo ao longo de suas vidas.

Se a abordagem da sexualidade for clara e consciente, pode-se até obter melhora na aprendizagem, já que os alunos encontram respostas às suas indagações, o que era nebuloso, se descortina muito límpido, sem tabus, sem preconceitos, ajudando-os a diminuir suas ansiedades, a entender seus conflitos, a descobrir a si mesmos, sendo ouvidos e respeitados em suas opiniões. Mas, se no contexto escolar não se reconhecer a sua importância e não se tratar da questão sexual estar-se-á omitindo e com esta atitude mostrando que o assunto é de fato um tabu, sobre o qual é melhor nem falar, que cada um aprenda à sua maneira. Mas, mesmo assim, alguma orientação sexual estará acontecendo, seja ela errada, opressiva ou preconceituosa. (SUPLICY et al., 1995, p. 10-14)

Por outro lado, muitas vezes a informação não garante a mudança de atitudes e valores, porquanto nem mesmo a informação que se tem sobre a DST/AIDS e gravidez precoce na adolescência impede o seu avanço e aumento, e como afirma Egypto (2003, p. 26-27):

A orientação sexual na escola não é garantia de que não vá ocorrer gravidez na adolescência, quando não planejada ou indesejada. Muitas vezes, a gravidez é uma fantasia da menina de que vai poder segurar o namorado, ou buscar na gravidez, e no fato de ser mãe, um papel social, respeito, um lugar social que a menina não tinha. As aulas ajudam muito a se conscientizar do problema, a 
encarar as resistências, as dificuldades e riscos, a superar preconceitos, mas não pode garantir que o comportamento aconteça.

Mas a instituição escolar tem o dever de intervir, de forma permanente e sistemática no desenvolvimento de atitudes de seus alunos, procurando compreender seus comportamentos no contexto amplo do desenvolvimento moral e social e quebrar preconceitos.

Há um número significativo de trabalhos direcionados a subsidiar os educadores quanto à abordagem da educação sexual. Contudo, observa-se que são poucas as escolas que incluem em suas práticas, um projeto desta natureza. Quando incluem, baseiam-se em palestras de psicólogos, enfermeiros e/ou médicos e em fixar, nos corredores, cartazes informativos sobre campanhas de prevenção de DST/AIDS, gravidez na adolescência e métodos contraceptivos, como se essas ações fossem suficientes para esclarecer as dúvidas e compreender as múltiplas expressões do tema. Sabe-se que falar sobre sexualidade por si só já é um desafio; as resistências são muitas, exigindo que todos os envolvidos revisem conceitos, superem preconceitos e estereótipos, olhem reflexivamente sobre a própria sexualidade, lidem com tabus, medos vergonhas.

A sexualidade faz parte da própria constituição intrínseca do ser humano, é uma manifestação ontológica da condição humana e é uma temática complexa. Falar e refletir sobre ela é desafiador; comumente não é abordada pelas instituições escolares permanecendo um campo onde perdura a incompreensão, a improvisação do senso comum, a repetição de preconceitos e quase sempre o descaso, embora vivamos numa sociedade em que frequentemente se exalta a infância como um período feliz e prazeroso da vida. O tema por ser dinâmico, sempre atual, vivencial e inesgotável requer contínua pesquisa e o alicerce de uma concepção científica e humanista que supere o senso comum.

Mas, de que maneira este tema é reinscrito dentro do contexto histórico e das demandas atuais? A reinserção dessa proposta parece estar associada a uma mudança nos padrões de comportamento sexual. Há necessidade de abordar com os jovens de todo o mundo esses temas e seus diversos desdobramentos, visando à prevenção da gravidez indesejada e das doenças sexualmente transmissíveis, máxime a AIDS. As intervenções mais eficazes são as ações educativas continuadas, que utilizam metodologia participativa e vão muito além do fornecimento de informações ou da prescrição de condutas preventivas.

A escola deve ter uma visão integrada das experiências vividas pelos alunos, buscando desenvolver o prazer do conhecimento e desempenhar um papel importante ao discutir assuntos que estão ligados à vida, à saúde, ao prazer e ao bem-estar que integra as diversas dimensões do ser humano envolvidas nesse aspecto. Ela não substitui a família e nem concorre com ela, mas possibilita a discussão de diferentes pontos de vista relacionados à sexualidade, sem a imposição de valores. Em nenhuma situação cabe à escola julgar a educação que cada família oferece a seus filhos. Como processo de intervenção pedagógica, tem por objetivo transmitir informações e 
problematizar questões relacionadas à sexualidade incluindo posturas, crenças, tabus e valores, sem invadir a intimidade nem direcionar o comportamento dos alunos.

Os trabalhos assistemáticos realizados dentro do contexto escolar obtêm resultados insignificantes; apenas informações não são suficientes para possibilitar a adoção de comportamentos preventivos. As intervenções mais eficazes são aquelas ações educativas continuadas, que possibilitam a elaboração das informações recebidas, a discussão dos obstáculos emocionais e culturais que impedem a adoção de condutas preventivas diante de problemas graves, como o abuso sexual e a gravidez indesejada. A escola não pode se omitir diante dessas questões, visto que só assim contribuirá para o bem-estar das crianças e dos jovens em sua vivência sexual atual e futura.

Uma pesquisa realizada pela Folha de São Paulo indicou que nos primeiros seis meses deste ano, na cidade de São Paulo, a cada dia, em média, duas meninas de menos de 14 anos se tornaram mães. Na faixa de 15 a 19 anos, a média diária sobe para 79 casos. E desde 2001 a situação permanece inalterada. Em apenas seis anos, nascerão perto de 200 mil crianças filhas de mães adolescentes, em sua maioria pobre. A maioria dessas meninas terá, em média, três filhos. Em bairros de periferia, de cada 1.000 adolescentes de 15 a 19 anos, cerca de 70 têm um filho por ano e dificilmente elas chegarão a fazer um curso superior. (DIMENSTEIN, 2004, p. 2)

Resultado: muitos indivíduos, mesmo num ambiente de crescimento econômico, terão dificuldades de inserção no mercado de trabalho. Estão condenados a viver na marginalidade, dependendo de verbas oficiais ou engrossando as fileiras do crime. No Brasil, nasce anualmente 1 milhão de filhos de adolescentes. A escola não deve constituir-se um espaço de educação para a vida, mas de educação na vida. Quem trabalha com sexualidade e prevenção da AIDS sabe que muito mais do que qualquer informação é necessário que crianças, jovens, adultos, homens e mulheres façam uso prazeroso e responsável do sexo e cuidem de sua própria saúde sexual.

É necessário haver espaço para que este tema seja perguntado, discutido, questionado e vivido de forma apropriada e singular. Evitar a gravidez precoce ou proteger-se contra DST é uma consequência da atitude de quem se valoriza no presente e aposta no futuro. Quem procede assim acaba aprendendo que a melhor camisinha está no cérebro, e não na genitália. Apesar do tema ser parte fundamental e integrante da vida de todos nós, o tabu a ele relacionado e as dificuldades para conversar sobre ele ainda são muito grandes.

A sexualidade é parte integrante da personalidade de cada um. É uma necessidade básica e um aspecto do ser humano que não pode ser separado dos outros aspectos da vida. Não é sinônimo de coito e não se limita à presença ou não de orgasmo. É muito mais do que isso, é a energia que motiva a encontrar o amor, o contato e a intimidade e se expressa na forma de sentir, na forma de as pessoas tocarem e serem tocadas. Influencia pensamentos, sentimentos, ações e interações e afeta tanto a saúde física como a mental. Se a saúde é um direito humano fundamental, a saúde sexual também deveria ser considerada como um direito humano básico. 
De acordo com os Parâmetros Curriculares Nacionais (BRASIL, 1997, v. 8, p. 111-115), o tratamento da sexualidade visa permitir ao aluno encontrar no contexto escolar um espaço de informação e de formação, sobre a maneira certa de tratar as questões colocadas pelo ambiente, um espaço que o ajude a considerar as dimensões biológica, psíquica e sociocultural da sexualidade.

Nem sempre os pais oferecem informações sobre esses assuntos, seja porque não possuem o conhecimento para fazê-lo, seja porque se sentem constrangidos. Mas o comportamento sexual é determinado pela organização e estrutura da família, pelas suas condições de vida, pela dinâmica das relações entre seus membros e pelas características individuais dos pais. Os pais no papel de educadores sexuais de seus filhos, muitas vezes procedem de forma inconsciente, sem avaliar o alcance das medidas que tomam, e de suas falas e das atitudes que assumem sobre questões direta ou indiretamente ligadas à vida sexual. Os filhos, porém, aprendem mais pelos atos do que pelos discursos de seus pais.

Grande parte da educação das crianças é determinada pelo comportamento dos pais em seu relacionamento e no relacionamento com os filhos, pelas proibições e recomendações que fazem, pelas expressões que assumem, pelos gestos que deixam transparecer, pelas atitudes conservadoras, liberais ou repressivas, pela religião que professam ou por não terem religião. Tudo isso transmite os valores que os filhos vão assimilando ao longo de sua vida.

A abordagem desta temática no âmbito da educação precisa ser: explícita para que seja tratada de forma simples e direta; ampla, para não reduzir sua complexidade; flexível para permitir o atendimento de conteúdos e situações diversas; e sistemática, para possibilitar aprendizagem e desenvolvimento crescentes.

"A educação sexual, como um processo social no âmbito escolar, poderá ser considerada como um processo de transformação e mudança, que parte de um projeto coletivo e atinge os indivíduos, cada qual com sua busca particular do(s) sentidos(s) da sexualidade". (LORENCINI JR, 1997, p. 95)

Discutir sexualidade e suas responsabilidades, como preconiza o Projovem Urbano, aponta para a necessidade de problematizar e esclarecer questões que beneficiam a reflexão e a ressignificação das informações, das emoções e valores recebidos e vividos no decorrer da história de cada um, que tantas vezes prejudicam o desenvolvimento de potencialidades. Essas discussões não ficarão reduzidas à abordagem dos aspectos biológicos, mas se estenderão a aspectos sociais, culturais, políticos, econômicos e psíquicos da sexualidade. Devem basear-se em toda prática educativa e levar a vários questionamentos. (BRASIL, 1997, v. 10, p. 121)

Envolver a prática educativa com essas reflexões e permitir que vários questionamentos sejam levantados exigem do professor flexibilidade, disponibilidade e abertura. Porém, qualquer que seja o componente curricular que ministram, os professores desempenham, consciente ou 
inconscientemente, uma ação no campo da educação sexual. Esta ação eles desenvolvem pela maneira de ser, de se vestir, de agir, pelas ideias e valores que transmitem e, particularmente, pelo tratamento que dispensam aos alunos de ambos os sexos. (MAISTRO, 2006)

Os adolescentes trazem noções e emoções sobre sexo, adquiridas em casa, em suas vivências e em suas relações pessoais, e dos meios de comunicação. Esse projeto deve considerar toda a gama de informações e sentimentos e possibilitar reflexão e debate, para que os alunos construam suas opiniões e façam suas escolhas.

Ribeiro (1990, p. 16) refere que:

Os valores e a história de vida que acompanham o indivíduo desde a infância estão de tal modo incorporados que dificilmente o jovem consegue viver sua sexualidade sem os tabus, os conflitos e os sentimentos de culpa, em consequência do confronto entre estes valores e os que a sociedade oferece hoje, entre as regras e o desejo. [...] recebendo informações distorcidas ou causadoras de dúvidas, o jovem não encontra espaço onde possa debater estas dúvidas e suas ansiedades, refletir sobre seus valores e conflitos, o que contribui para não conseguir viver sua sexualidade sem medo e sem culpa.

Nos dias atuais não é mais possível que as questões relacionadas à sexualidade passem despercebidas ou sejam tratadas com malícia ou como algo pecaminoso e imoral. Então é importante tratar o tema a fim de proporcionar aos jovens um desenvolvimento mais equilibrado da sua personalidade, possibilitando-lhes escolhas mais responsáveis sobre seu corpo e para conseguir esse objetivo é necessário tratar esse assunto interdisciplinarmente.

O relacionamento interdisciplinar permite que todas as áreas do conhecimento estejam articuladas e tratem da temática com a finalidade de ampliar conhecimentos. Quanto ao envolvimento de todas as disciplinas, Reichelmann (1993, p. 282) tem este entendimento: "Abordar sexualidade exige um exercício de interdisciplinaridade. Por vezes ela é enfocada de modo reducionista, limitado ao terreno do biológico, ou há tentativas de se confundir sexualidade com algo limitado à biologia, psicologia ou à sociologia".

Hoje já há uma preocupação em discutir a sexualidade nas instituições escolares, buscando-se explicar não só os aspectos biológicos da sexualidade, mas também aspectos médicos e psicológicos. Estamos mais conscientes e sabedores de que a sexualidade se faz presente em todas as etapas de nosso desenvolvimento de seres humanos e à medida que passamos a refletir sobre ela e a conhecermos melhor, crescemos na autoconfiança e autoestima melhorando a qualidade de vida e relacionamento interpessoal. (MAISTRO, 2006)

Existe uma preocupação quanto a que reflexões e discussões sobre sexualidade aconteçam nas escolas, já que na mídia, de uma forma ou de outra, o tema sexualidade está 
sendo apresentado ou de modo exacerbado, ou quando se veiculam denúncias relevantes sobre sexo, pedofilia, prostituição infantil, ou se apresentam programas que colocam em evidência matérias de comportamento para que as pessoas se divirtam e esclareçam suas dúvidas com informações sobre outras culturas ou sobre resultados de pesquisas atuais.

Seria muito importante que a família se dispusesse a buscar informações e refletisse sobre a sexualidade e sobre a melhor forma de lidar com esse assunto, pois é obrigação dos pais educar seus filhos para a vida e, por essa razão, eles não podem se contentar com uma educação dissociada na qual se valoriza o intelectual, o social, o espiritual, deixando-se de lado o afetivosexual. Evidenciar este assunto como os outros é respeitar o filho de forma integrada e ajudá-lo a superar problemas que envolvem o sexo e a sexualidade.

Seria ideal que a família desse ao filho mais oportunidade de falar o que pensa e sente, uma vez que é ela que the está mais próxima diariamente e, por essa razão, ela conseguiria melhor que qualquer outra instituição orientar o filho. Mas sabe-se que muitos pais não tiveram maior contato com o tema sexualidade para se sentirem aptos a lidar com esses assuntos com os seus filhos.

Daí a importância de levar para o âmbito escolar a discussão sobre os mais variados temas que envolvem a sexualidade, em razão de os pais não se sentirem preparados para falar de sexo com os filhos, em razão também dos elevados índices de gravidez precoce e/ou indesejada, em razão das altas taxas de DST/AIDS, em razão ainda de tantos livros, revistas, músicas, televisão, rádio, imprensa, internet, programas de computador e muitos outros canais de cultura e informação informarem os jovens, quando os professores é que seriam as pessoas mais indicadas para tratar desses assuntos, por terem mais facilidade de propor debates e diálogos, permitindo que os alunos exponham seus sentimentos, dúvidas e ansiedades.

Mas, o contexto escolar está preparado para tal iniciativa, para abrir canais de comunicação, de espaço para se falar sobre a sexualidade de forma descontraída, prazerosa, com clima de confiança e liberdade?

A sexualidade se manifesta diariamente às claras ou reservadamente; por isso é necessário falar desse assunto como de qualquer outro, apesar de sabermos dos limites e das possibilidades que o assunto enseja.

Portanto, a reflexão sobre a temática em pauta propõe-se a ampliar, diversificar e aprofundar a visão sobre as questões referentes ao sexo, abordando os diferentes pontos de vista da sociedade e incluindo as práticas sexuais ligadas ao afeto, ao prazer, ao respeito e à própria sexualidade. Também propõe-se a preencher lacunas de informação, mexer com os tabus e preconceitos e erradicá-los, e a permitir discussões sobre as emoções e valores da sexualidade e cooperando para a formação de opiniões corretas. 
Tratar da sexualidade e da responsabilidade dos pais e da escola não é apenas dar informações sobre a reprodução ou prevenção, pois a sexualidade tem uma dimensão histórica, cultural, ética e política que abrange todo o ser: corpo e espírito, razão e emoção, podendo expressar-se de diversas formas: por carícias, beijos, abraços, olhares; também não se limita a ser só instrumento preventivo da AIDS, da gravidez precoce, do aborto e das DST. Assim, ela abrange o desenvolvimento sexual compreendido como: saúde reprodutiva, relações de gênero, relações interpessoais, afetivas, imagem corporal e autoestima, propiciando uma visão mais ampla, profunda e diversificada da sexualidade.

Quanto a isso, Ribeiro (1990, p. 18) expõe:

Torna-se necessário abordar a orientação sexual criticamente, de forma que ela reflita a sexualidade partindo de um enfoque sociocultural, passando pelo psicológico, até chegar aos aspectos fisiológicos, sempre levando em consideração a importância fundamental do diálogo, ampliando o senso crítico e a visão de mundo do jovem, permitindo discussões e debates.

Nesse sentido, Sayão, Y. (1997, p. 107-117) diz que, de uma forma ou de outra, o contexto escolar interfere na construção da sexualidade de cada aluno; sendo assim, "que ela reflita sobre o seu papel, e ao abordar esse tema o faça de forma consciente e profissional".

No projeto Projovem Urbano, há um tema integrador - Relações Sociais Desiguais e Vida do Jovem - que sugerem desdobramentos ao longo das unidades formativas, várias temáticas e em especial na unidade formativa IV, recomenda a sexualidade e a responsabilidade como prática educativa, e que cada uma das áreas trate da temática de acordo com sua própria proposta de trabalho. Estes encaminhamentos tratam da temática como algo fundamental na vida das pessoas, uma vez que é no contexto escolar que podem originar vínculos significativos entre alunos e professores, e é ali que se encontra ambiente acolhedor e clima de respeito. É nesse ambiente que se adquirem informações e maior consciência da autonomia pessoal e, ao longo do processo pedagógico, uma melhor compreensão dos movimentos políticos e culturais que envolvem a sexualidade, questão ampla e polêmica, marcada pela história, pela cultura e pela evolução social.

Nos cursos de formação continuada dos educadores do Projovem Urbano, foram discutidos vários temas referentes à sexualidade, já que se sabe da necessidade da formação dos profissionais nessa questão. Compreende-se que é difícil trabalhar de maneira efetiva qualquer temática que seja polêmica dentro da educação se os educadores não tiverem a sensibilidade e a preparação necessárias para conhecer os principais problemas que afetam a sociedade em geral e os alunos em particular. Reconhece-se que muito se exige dos educadores, por isso é necessário que possuam estratégias metodológicas apropriadas para abordar os temas atuais, tenham conhecimentos básicos e suficientes para definir os objetivos, os conteúdos, a metodologia e a 
avaliação, pois deles depende o currículo que será elaborado: o que, quando e como ensinar. (GAVIDIA, 2002, p. 27)

\section{Espaços de construção e reflexão}

Ao proporcionar aos alunos um espaço de reflexão, o Projovem Urbano estimula discussões, levando em conta o interesse e a curiosidade dos jovens.

Suplicy et al. (1995, p. 13) nos falam em "abrir canais de comunicação". Entendemos que, neste momento, o projeto Projovem Urbano abre espaço para que a temática seja discutida, com o objetivo de colaborar para que os alunos se transformem refreando suas agressões e exibicionismo; toca num aspecto vital do amadurecimento mental e da formação da personalidade e possibilita maior tranquilidade em meio ao turbilhão da adolescência. $O$ aluno se sente valorizado, quando percebe que o Projovem Urbano, no momento em que insere a temática da sexualidade no currículo, busca esclarecer-lhe as angústias, mostrando que está realmente preocupado com ele, com seu bem-estar, que está querendo ajudá-lo a descobrir-se e a inserir-se no seu mundo.

Nesse sentido, ele se sente realmente como um cidadão, pois percebe que este projeto está procurando meios de compreendê-lo, de orientá-lo nas reflexões, de abrir espaços para discussões de assuntos tabus, os quais muitas vezes são os mais importantes para ele, por ajudálo a conhecer-se a si mesmo, a vencer barreiras e preconceitos, por permitir-lhe liberdade de escolha e por entender e valorizar as experiências, sentimentos e mensagens (mesmo implícitas). A sexualidade faz parte da nossa existência e, como diz Catonné (2001, p. 100), "o projeto de uma bela existência implica o de uma livre sexualidade".

\section{A transversalidade ocorrendo silenciosamente}

A sexualidade, dotada de uma transversalidade inerente, pode fazer parte de todos os processos de construção do conhecimento. Talvez essa transversalidade já ocorra genuína e silenciosamente dentro das diversas áreas do saber. Ela é colocada em pauta todos os dias, inconscientemente, pela emergência de valores, posturas e visões de mundo dos que participam do cotidiano escolar. Dentro dessa perspectiva, seja no discurso verbalizado, seja no discurso silencioso, ela está percorrendo o currículo. De acordo com Gavidia (2002, p. 20), “a transversalidade é uma proposta séria, integradora, não repetitiva, que contextualiza a problemática formulada pelas pessoas nesse momento, como indivíduos e como grupo. [...] é aquilo que se estende atravessado de um lado a outro, "encadear", "transpassar", "infiltrar-se".

Na busca de entender essa transversalidade, Yus (2002, p. 40-41) ressalta que ela não pode ser aceita como uma lista de temas desconexos, mas deve ser o espírito, o clima e o 
dinamismo humanizador da escola; que existem certos elementos comuns que funcionam como elos com implicações nas práticas educativas. E esses elementos:

- Procuram promover visões interdisciplinares globais e complexas que facilitem a compreensão de fenômenos dificilmente explicáveis a partir da ótica de uma disciplina.

- Pretendem romper com as visões dominantes, que não são somente as transmitidas pelo poder, mas que acabam justificar o etnocentrismo, o androcentrismo e a reprodução de injustiças e de desigualdades.

- Expressam a necessidade de conseguir aulas plenamente cooperativas $e$ participativas, em que os alunos sintam-se envolvidos em seu processo de aprendizagem e em que os professores não sejam meros profissionais, mais ou menos técnicos e hábeis no manejo das habilidades de ensino, mas agentes criadores do currículo, intelectuais e críticos.

- Reconhecem a importância de se conectar com a vida, de provocar empatia, de fazer um levantamento das preocupações socioafetivas das meninas e dos meninos que formam o nosso alunado.

No momento em que a escola abre portas para que um projeto dessa natureza se concretize, inserindo em sua programação sexualidade e responsabilidade, ela está sendo solidária com a comunidade que pretende atingir, propondo-se a esclarecer determinados problemas, como gravidez precoce na adolescência, doenças sexualmente transmissíveis e, principalmente, a valorização da saúde de cada um dos educandos por compreender que a maior fonte de informação do adolescente é o seu companheiro de mesma idade ou ligeiramente mais velho, fonte essa que, na maioria das vezes, é inadequada, uma vez que seu companheiro tem conhecimentos distorcidos a respeito da sexualidade. (MAISTRO, 2006)

Reconhecemos a importância do Projovem Urbano ocupar-se dessa temática visando à orientação dos alunos quanto ao desenvolvimento e exercício de uma sexualidade prazerosa e responsável. Esse tema está ligado intimamente ao exercício da cidadania, quando se trabalha o respeito que o aluno deve ter por si e pelo outro e quando há empenho para que os direitos básicos do cidadão, como a saúde, a informação e o conhecimento, sejam respeitados.

O exercício da cidadania que o Projovem Urbano estimula, além de garantir a dignidade do ser humano, favorece o respeito à diversidade de valores, crenças e comportamentos relativos à sexualidade, ajudando a compreender a sua dimensão saudável, a desenvolver uma consciência crítica e a tomar decisões responsáveis a respeito da sexualidade.

Se uma das propostas do Projovem Urbano é aliar formação e ação e se ele acontece num lugar institucionalizado socialmente, a escola, e se este ambiente é um espaço sexualizado, atravessado pelas concepções de masculinidade e feminilidade, pelas formas de sexualidade de 
uma dada sociedade, é essencial um aprofundamento sobre tais questões, permitindo que as dúvidas quanto a ela sejam abordadas sem preconceitos, para que todos possam se informar, refletir, debater, questionar, de maneira clara e objetiva, respeitando as individualidades. Somente assim este projeto estará cumprindo seu relevante papel social na formação dos indivíduos.

O contexto escolar desempenha um papel importante na orientação dos alunos independente das intervenções formais que se fazem neste campo. Mas ainda percebemos que existem instituições que reprimem certos comportamentos dos alunos. Nem sempre os educadores enfrentam com serenidade e com o tato necessário brincadeiras e comportamentos de ordem sexual, conferindo-Ihes uma gravidade e um caráter que na realidade não têm. Ninguém pode fugir a essa responsabilidade, afirmando incapacidade ou dificuldade em tratar esse assunto, diante dos bilhetinhos e das conversas dos alunos sobre sexualidade. Quando os educadores não tratam esse assunto de frente, quando se omitem, estão permitindo que ele continue a ser tratado só informalmente, na rua ou em casa, sem uma orientação segura.

Não é uma tarefa fácil, mas é necessário e urgente que políticas educativas voltadas para a temática da sexualidade sejam propostas, debatidas, valorizadas e acompanhadas de um conjunto de ações que serão necessárias para efetivá-las, abordando-se as questões relacionadas ao tema de forma a abranger todos os aspectos envolvidos. Esta ação teria como finalidade, não só informar, mas também desenvolver as habilidades necessárias à utilização destas informações para o exercício saudável da sexualidade.

Por consequência, é essencial saber que a discussão sobre sexualidade e responsabilidade deve ter propósito de trabalho o desenvolvimento de uma metodologia participativa e criativa, que ultrapasse o campo das intenções, tratando com clareza os assuntos, uma vez que os jovens trazem noções e emoções sobre sexo, adquiridas em casa, em suas vivências e em suas relações pessoais, e através dos meios de comunicação. Portanto, esse projeto deve considerar toda a gama de informações e sentimentos e possibilitar reflexão e debate, para que os alunos construam suas opiniões e façam suas escolhas.

Quanto mais um projeto estiver relacionado a uma necessidade ou a uma urgência social, quanto mais a problemática enfocada no projeto estiver relacionada com o contexto da própria comunidade escolar, quanto mais temas relacionados com a sexualidade se configurarem como problemas urgentes - reclamando, se não solução (gravidez na adolescência, violência sexual, doenças sexualmente transmissíveis, e outros), pelo menos discussão e reflexão -, e quanto mais educadores, alunos e pais vivenciarem esses problemas, mais o projeto terá resultados significativos e positivos no que tange à mudança de valores, às atitudes e ao exercício efetivo da cidadania.

Podemos inferir que este trabalho é necessário e pode ser levado à frente desde que se leve em consideração a sua essencialidade, se esteja aberto a mudanças, se aceitem e assumam 
novas opiniões e pensamentos, se transponham preconceitos e tabus e se permita que o aluno discuta com naturalidade os problemas que o afligem. Não é um trabalho que um professor faça sozinho nem se sustenta apenas com voluntariado; ele tem de ser discutido pela equipe e supõe planejamento e estudos contínuos, com supervisão e o envolvimento de todos, porquanto é de suma importância.

As questões apontadas ao longo deste estudo não prescindem de um esforço conjunto e requerem, portanto, a formação dos professores, trabalho contínuo com os pais, informação permanente dos alunos e dos pais, diversificação da metodologia e construção de um programa sólido. Outros aspectos necessitam ser dimensionados, ainda, tais como: diminuição das distâncias entre professores, pais e alunos, formação de vínculos, envolvimento de maior número de pessoas tanto pertencentes à comunidade escolar quanto de outros setores da sociedade, enfrentamento de determinados assuntos tidos como "polêmicos", e principalmente olhar com "outros olhos" a sexualidade como fonte de legítimo prazer desde que assumida com responsabilidade.

A inclusão de temas integradores que promovem e induzem à reflexão sobre sexualidade tem sua complexidade, e esta prática pedagógica é de suma importância e de extrema urgência. Um projeto desta natureza permite estudos por toda a comunidade educativa, deve ser um processo de reflexão sobre o que a educação tem feito sobre a temática da sexualidade para que a melhoria da qualidade do ensino resulte da corresponsabilidade entre todos os educadores e que se repense o papel e a função da instituição escolar.

Hoje há uma preocupação geral em discutir a sexualidade dos jovens nas instituições escolares, buscam-se nos diferentes campos do conhecimento informações relacionadas às transformações físicas, psicológicas, emocionais, biológicas como recurso para a educação sexual. Estamos mais conscientes e sabedores de que a sexualidade está presente em todas as etapas de nosso desenvolvimento e, à medida que passamos a refletir sobre ela e a conhecer melhor, crescemos na autoconfiança e na autoestima melhorando a qualidade de vida e o relacionamento interpessoal.

As comunidades escolares possuem realidades diferentes e, assim, o projeto necessita atender as especificidades de cada um, ou seja, ele precisa moldar-se às necessidades dessa realidade. A partir do momento em que se toma consciência de um problema, de sua relevância no contexto social e escolar, da necessidade de capacitação para discuti-lo com maior segurança e do envolvimento de um maior número de pessoas, passa-se a ter mais habilidade e confiança para poder enfrentar e discutir problemas relacionados à sexualidade, no processo de um projeto.

Somente a informação não muda comportamentos. Falar sobre sexualidade por si só já é um desafio; as resistências são muitas, exigindo-se de todos os envolvidos a revisão de conceitos e a superação de preconceitos e estereótipos. Olhar reflexivamente sobre a própria sexualidade é delicado e embaraçoso. Lidar com tabus, medos, vergonhas requer muito preparo e habilidade. 
Tudo isto não é nada fácil! Mas só existe aprendizagem quando há estudo sério e reflexão, quando se coloca em ação tudo aquilo que foi refletido. O caminho é longo e interessante. E nada está pronto, concluído e esgotado.

\section{Referências}

BRASIL. Ministério da Educação e Cultura. Secretaria de Educação Fundamental. Parâmetros curriculares nacionais: pluralidade cultural e orientação sexual. Brasília, 1997. v. 8, v. 10.

CATONNÉ, J. P. A sexualidade, ontem e hoje. 2. ed. São Paulo: Cortez, 2001. (Questões da nossa época, v. 40)

DIMENSTEIN. G. Camisinha de cérebro. Folha de São Paulo, São Paulo, 17 out. 2004. Cotidiano, p. 2.

EGYTO, A. C. (Org.) Orientação sexual na escola: um projeto apaixonante. São Paulo: Cortez, 2003.

GAVIDIA, V. A construção do conceito de transversalidade. In: ÁLVAREZ, M. N. et al. Valores e temas transversais no currículo. Tradução por Daisy Vaz de Moraes. Porto Alegre: Artmed, 2002. p. 15-30. (Inovação Pedagógica, v. 5)

LORENCINI JÚNIOR A. Os sentidos da sexualidade: natureza, cultura e educação. In: AQUINO, J. G. (Org.). Sexualidade na escola: alternativas teóricas e práticas. São Paulo: Summus, 1997. p. 87-95.

MAISTRO, V. I. A. Projetos de orientação sexual: seus limites e suas possibilidades. 2006. Dissertação (Mestrado em Ensino de Ciências e Educação Matemática) - Centro de Ciências Exatas, Universidade Estadual de Londrina, Londrina.

OLIVEIRA, A. R.; LYRA, J. Fazendo gênero 8 - Corpo, violência e poder. Direitos sexuais e reprodutivos de adolescentes e as políticas públicas de saúde: desafios à atenção básica. ST 40 Estado Laico, Sexualidade e Políticas Públicas. Florianópolis de 25 a 28 ago. 2008.

REICHELMANN, J. C. A educação sexual no sistema de saúde. In: RIBEIRO, M. (Org.). Educação sexual: novas ideias, novas conquistas. Rio de Janeiro: Rosa dos Ventos. 1993. p. 281-303.

RIBEIRO. P. R. M. Educação sexual além da informação. São Paulo: EPU, 1990.

SAYÃO, Y. Orientação sexual na escola: os territórios possíveis e necessários. In: AQUINO, J. G. (Org.). Sexualidade na escola: alternativas teóricas e práticas. São Paulo: Summus, 1997. p. 87-95. SUPLICY, M. et al. Sexo se aprende na escola. São Paulo: Olho d'Água, 1995.

YUS, R. Temas transversais e educação global: uma nova escola para um humanismo mundialista. In: ÁLVARES, M. N. et al. Valores e temas transversais no currículo. Tradução por Daisy Vaz de Moraes. Porto Alegre: Artmed, 2002. p. 31-48. (Inovação Pedagógica, v. 5) 
Vera Lucia Bahl Oliveira - Docente da UEL no Dep. de Ciências Biológicas Disciplina: Metodologia e Prática de Ensino - verabahl@sercomtel.com.br

Virginia lara Andrade Maistro - Docente da UEL no Dep. de Ciências Biológicas Disciplina: Metodologia e Prática de Ensino - virginiamaistro@yahoo.com.br 